Low Status Groups Show In-Group Favoritism to Compensate for their Low Status and Compete for Higher Status

Mark Rubin

The University of Newcastle, Australia

Constantina Badea

Université Paris Ouest Nanterre La Défense, France

and

Jolanda Jetten

University of Queensland, Australia

The APA $\left(6^{\text {th }}\right.$ ed $)$ style reference for this article is as follows:

Rubin, M., Badea, C., \& Jetten, J. (2014). Low status groups show in-group favoritism to compensate for their low status and to compete for higher status. Group Processes and Intergroup Relations, 17, 563-576. doi: $\underline{10.1177 / 1368430213514122}$

This self-archived version is provided for non-commercial and scholarly purposes only.

Correspondence concerning this article should be addressed to Mark Rubin at the School of Psychology, The University of Newcastle, Callaghan, NSW 2308, Australia. Tel: +61 (0)2 4921 6706. Fax: +61 (0)2 4921 6980. E-mail: Mark.Rubin@newcastle.edu.au 


\begin{abstract}
The present research investigated the intergroup allocation behavior of members of low status groups. In two studies where status relations were either relatively illegitimate (Study 1, $N=139$ ) or legitimate (Study 2, $N=114$ ), undergraduate students completed a minimal group resource allocation task that took into account the intergroup status hierarchy. In both studies, members of low status groups showed two forms of in-group favoritism. They selected resource allocation choices that (a) compensated for their low status and led to intergroup fairness (compensatory favoritism) and (b) competed with the out-group for status and led to positive distinctiveness for the in-group (competitive favoritism). These results suggest that members of low status groups use in-group favoritism to make their group (a) as good as the high status out-group and (b) better than the high status out-group. The findings support the idea that in-group favoritism can serve different functions.
\end{abstract}

KEYWORDS: in-group favoritism; intergroup fairness; low status groups; social identity theory; minimal group. 


\section{Low Status Groups Show In-Group Favoritism to \\ Compensate for their Low Status and to Compete for Higher Status}

Group status refers to the relative position of a group on an evaluative dimension based on intergroup comparisons with other relevant social groups (e.g., Tajfel \& Turner, 1979). Previous research has demonstrated that members of low status groups sometimes show out-group favoritism (e.g., Riechl, 1997; Sachdev \& Bourhis, 1987, 1991; Turner \& Brown, 1978) and sometimes show in-group favoritism (e.g., Branthwaite, Doyle, \& Lightbown, 1979; Commins \& Lockwood, 1979b; Klein \& Azzi, 2001; Mummendey et al., 1992; Reichl, 1997; Sachdev \& Bourhis, 1984; Scheepers, Spears, Doosje, \& Manstead, 2006; Turner \& Brown, 1978; van Knippenberg, 1984; for reviews, see Bettencourt, Charlton, Dorr, \& Hume, 2001; Brewer, 1979; Mullen, Brown, \& Smith, 1992). Key moderators of these in-group and out-group favoritism effects are the stability and legitimacy of the intergroup status hierarchy (Tajfel \& Turner, 1979). When status relations are perceived to be unstable and illegitimate, members of low status groups tend to show in-group favoritism (e.g., Bettencourt et al., 2001). In contrast, when status relations are perceived to be stable and legitimate, members of low status groups tend to show out-group favoritism, especially on statusrelevant dimensions (Bettencourt et al., 2001; Mullen et al., 1992).

Low status groups' out-group favoritism has generated considerable debate and discussion in the literature because it represents a theoretically-important exception to the more common in-group favoritism effect (Jost et al., 2004; Rubin \& Hewstone, 2004). Following social identity theory, Rubin and Hewstone (2004) conceptualize this low status group out-group favoritism as consensual discrimination because it reflects consensual perceptions of intergroup status that are held by members of both the high and low status groups. In contrast, Jost, Nosek and Banaji (2004) contend that low status group's out-group favoritism represents a more active attempt to justify the intergroup status system.

While researchers have focused on understanding the theoretical implications of low status groups' out-group favoritism, much less theoretical consideration has been devoted to understanding the nature of low status groups' in-group favoritism. The present research redresses this balance by considering two different functions of low status groups' in-group favoritism: (a) compensating for current inequality and (b) competing for future status.

\section{Why do Low Status Groups Engage in In-Group Favoritism?}

The dominant explanation for low status groups' in-group favoritism is based on social identity theory (Tajfel \& Turner, 1979). According to this theory, members of low status groups engage in in-group favoritism in order to elevate the status of their ingroup beyond that of high status out-groups. In other words, in-group favoritism is used in a rather instrumental manner (Scheepers et al., 2006) to reverse the intergroup status 
hierarchy so that the originally low status in-group becomes a high status group and the originally high status out-group becomes a low status group. This social competition (Turner, 1975) is motivated by the desire to attain a positive distinctiveness for the ingroup and a concomitant positive social identity for the self.

However, there is a second, less considered reason why members of low status groups may engage in in-group favoritism, and that is to elevate the status of their ingroup in order for it to become equivalent to (and not necessarily higher than) that of high status out-groups. In this case, in-group favoritism is used to achieve intergroup fairness rather than positive distinctiveness for the in-group. This goal of intergroup fairness may be explained in terms of a socially desirable norm (Branthwaite et al., 1979; Singh, Choo, \& Poh, 1998), a hierarchy-attenuating ideology (Pratto, Sidanius, Stallworth, \& Malle, 1994), and/or an interpersonal social value orientation (Platow, McClintock, \& Liebrand, 1990).

In summary, it is possible that low status groups' in-group favoritism serves two functions. It can be used to compete with the high status out-group in order to achieve positive in-group distinctiveness. We refer to this strategy as competitive favoritism. It can also be used to compensate the in-group for its low status in order to achieve intergroup fairness. We refer to this strategy as compensatory favoritism. ${ }^{1}$ Hence, competitive favoritism elevates low status in-groups to a level that is better than relevant out-groups, and compensatory favoritism elevates low status in-groups to a level that is the same as relevant out-groups.

\section{Previous Research}

The subtleties of intergroup behavior have been investigated most commonly using intergroup resource allocation tasks in the minimal group paradigm (e.g., Turner \& Brown, 1978). However, the allocation system in these studies has not always provided an explicit determination of subsequent status relations between high and low status groups (e.g., Sachdev \& Bourhis, 1987). Furthermore, in those cases in which this determination has been made explicit, the allocation system has not reflected the initial status relations (e.g., Commins \& Lockwood, 1979a, 1979b; Scheepers et al., 2006).

To illustrate, Sachdev and Bourhis (1987) randomly assigned participants to high and low status groups on the basis of false feedback on a creativity task. Participants then used points allocation matrices to rate the creativity of in-group and out-group members based on their performance on a second creativity task. In this research paradigm, the researchers were able to ascertain the effect of group status on in-group favoritism. However, it is unlikely that participants perceived a link between their points ratings of in-group and out-group members and the subsequent status of the in-group and out-group: Awarding relatively larger numbers of points to one's fellow in-group members in order to endorse their creativity does not change the in-group's 
objective standing on the creativity dimension (For a related discussion, see Scheepers et al.'s, 2006, distinction between symbolic and material in-group bias).

Scheepers et al. (2006, Experiment 1) overcame this disconnect between the allocation system and subsequent intergroup status. Their participants were randomly assigned to one of two groups on the basis of false feedback on a dot estimation task. In an experimental manipulation of group status, participants were told that the people in one of the groups were more accurate estimators (high status) than the people in the other group. Participants then allocated feedback opportunities to in-group and outgroup members using points allocation tables. Participants understood that group members could use these feedback opportunities to enhance their accuracy during a second estimation task. Hence, in this paradigm, the allocation system had the potential to change the intergroup status hierarchy. For example, awarding more feedback opportunities to members of the low status group was likely to improve the estimation performance of this group beyond that of the high status group, potentially reversing the original status positions of the two groups. Critically, however, the initial intergroup status hierarchy was not represented in the allocation system. So, for example, the feedback allocation task did not take into account the fact that the members of the low status group would need more feedback opportunities than the members of the high status group in order to reach an equivalent level of estimation performance as the high status group. Consequently, although the allocation system had the potential to change the future intergroup status hierarchy, it was detached from the current intergroup status hierarchy.

A similar problem is evident in Commins and Lockwood's (1979a, 1979b) research. These researchers awarded some minimal group members an initial points advantage and others an initial disadvantage. Participants then distributed points between in-group and out-group members using standard points allocation tables. Participants in most conditions showed in-group favoritism even after their initial points advantage or disadvantage was taken into account. These results suggest the occurrence of competitive favoritism. Again, however, the points allocation tables did not reflect the existing intergroup points advantages and disadvantages, and so they could not be used to determine the extent to which compensatory favoritism was occurring.

In the real world, intergroup status hierarchies are often inextricably embedded in intergroup resource allocation systems. For example, in the USA, women are paid $78 \%$ less than men who undertake similar jobs (National Organization for Women, 2013). In this context, in order to make judgements of fairness and equity, pay increases to women need to be compared with not only pay increases to men, but also the pay deficit with men. Hence, a gender pay allocation task that ignores this deficit can be criticized for being disconnected from the social reality of the intergroup situation, lacking ecological validity, and confounding competitive and compensatory favoritism. For example, a standard resource allocation task might show that female 
participants award more money to women than to men, and researchers might interpret this effect as competitive favoritism. In contrast, when women's initial pay deficit is embedded into the allocation system, researchers are able to reinterpret this effect as compensatory favoritism: Female participants award more money to women than to men in order to achieve equal pay for both.

\section{Overview of the Present Research}

The present research aimed to address the limitations of previous research in this area by bridging the disconnect between the allocation system and the status system. In doing so, we aimed to provide a more ecologically valid analysis of in-group favoritism and determine the extent to which competitive and compensatory favoritism form the basis for low status groups' in-group favoritism.

To achieve this aim, we developed a set of minimal group resource allocation tables that tied allocation behavior more clearly to a prevailing intergroup status hierarchy and made it possible to change this hierarchy in a way that distinguished between competition and compensation. In our new status-embedded points allocation tables, low status groups started with fewer points than high status groups, and the number of points that groups acquired during the points distribution task was explicitly linked with their final status. If low status groups' in-group favoritism is intended to make the in-group better than the out-group (i.e., social competition), then group members should prefer competitive choices in this type of task. In contrast, if low status groups' in-group favoritism is intended to make the in-group equal to the outgroup (i.e., intergroup fairness), then group members should prefer compensatory choices. Finally, it is possible that low status groups' in-group favoritism reflects a balance between social competition and intergroup fairness (e.g., Branthwaite et al., 1979; Singh et al., 1998), in which case group members should choose both competitive and compensatory choices.

We conducted two studies to test our predictions. In the first study, we designed an intergroup status hierarchy that was relatively illegitimate. This study enabled us to provide a powerful test of social identity theory's social competition prediction. In the second study, we designed an intergroup status hierarchy that was relatively legitimate. This second study allowed us to test whether low status groups' compensatory and/or competitive favoritism persisted under conditions that are typically considered to be less conducive for social change. Hence, we investigated whether compensatory and/or competitive favoritism generalized from an illegitimate intergroup status hierarchy in Study 1 to a more legitimate one in Study 2.

In order to demonstrate that our results were specific to members of low status groups, we compared the responses of participants who were assigned to a low status group with the responses of participants who were assigned to a high status group or to no group (control condition). 
Method

\section{Study 1}

Participants. Participants were 139 psychology undergraduate students (36 men, 103 women) at a French university who had a mean age of 21.33 years $(S D=$ 3.75). There were 48 participants in the low status group, 47 in the high status group, and 44 in a control condition, who belonged to neither group.

Procedure. Participants completed a paper-and-pencil survey individually on the university campus. All materials were presented in the French language.

Participants read that there were 100 people taking part in the study, and that a computer had randomly assigned 50 to a group called the "Red Group" and 50 to a group called the "Green Group". Each person in each group was identified by a membership number from 1 to 50 .

Participants in the high and low status group conditions were then assigned to a group and provided with a membership number. In order to prevent group names from confounding conditions, all participants were given the same group and membership number information (member number 36 of the Red Group). Participants in the control condition were not assigned to a group or given a membership number.

Participants read that the research was investigating how people allocate resources to people in different social groups when the groups start off with different amounts of those resources. They read that the resources consisted of points that they should think of as points in a game in which the more points a person or group gets the better. It was explained that the researchers would add up the total number of points that each group had been allocated at the end of the research in order to determine which group had the most points. Hence, the allocation of points was explicitly linked with each group's social status.

The appendix shows the status-embedded points allocation tables that were used in the low status group condition. The tables that were used in the high status and control conditions were identical except that the words "Red" and "Green" were interchanged.

The first column of each table was labelled "Person Identification", and it included the membership numbers and groups of the two people who would receive points from the table. In order to prevent personal self-interest from influencing our results, participants' own membership number was not included as a recipient in any of the tables.

The second column was labelled "Each Person's Starting Points", and it indicated the number of points that the two people in the table started with. Participants read that a computer had allocated between 0 and 9 points to each person, and that it had always allocated two more points to members from one of the two groups. It was at this stage that we experimentally manipulated group status. Participants in the low status condition read that members of the Green group (i.e., the out-group) always started the 
game with two more points than members of the Red Group. In contrast, participants in the high status and control conditions read that Red Group members (i.e., in-group members for the people in the high status group condition) always started the game with two more points than Green Group members. Note that we did not provide participants with any reason for this unequal distribution of starting points. Hence, we expected them to find this intergroup status system to be relatively illegitimate.

The next four columns in each table were labelled "My Allocation to Each Person", and they provided four points allocation choices. Participants selected one choice in each table by drawing a circle around one of the four columns.

Above each table there was a box labelled "Total Needed for Bonus Points". This box indicated the total number of points that each person needed to meet or exceed in order to receive a bonus that was worth double their points. So, for example, the first table in the appendix indicates that the total needed for the bonus points is 11 points. Participants were told that they could calculate whether either person in the table had met this total by adding the person's starting points to the number of points that they had been awarded in the table. So, for example, in the first table, if participants circled the first choice (i.e., 5/3), then member number 45 of the Green Group would receive 5 points in addition to the 8 points that they started with, making a total of 13 points. This total exceeds the total needed for bonus points (11), and so member number 45 of the Green Group would be awarded a final total of 26 points (i.e., 13 x 2). Meanwhile, member 50 of the Red Group would receive 3 points in addition to the 6 points that they started with, making a total of 9 points. This total does not meet or exceed the total needed for bonus points (11), and so the Red Group member's final points total would be 9 points.

This points allocation system was intended to provide a clearer understanding of the function of low status group members' in-group favoritism. By making an explicit connection between the number of points that groups possessed and each group's status, we provided participants with the opportunity to change the intergroup status hierarchy by awarding one group more points than the other. In addition, by embedding the intergroup status hierarchy (i.e., the difference in each group members' starting points) into the points allocation tables, we were able to contrast choices that compensated for the low status group's initial disadvantage and contributed towards intergroup fairness with choices that competed with the out-group and contributed towards a reversal of the intergroup status hierarchy. For example, in the first table in the appendix, the second choice (3/5) compensated the member of the low status (Red) group for their initial points disadvantage and allowed the members of both the high and low status groups to reach the 11 point threshold for bonus points. In contrast, the fourth choice (2/6) allowed the member of the low status group to compete by ensuring that they were the only person to meet the threshold for bonus points.

Each table also included two choices that favored the high status group. We 
included these choices in order to allow for the possibility that members of low status groups might engage in out-group favoritism in order to either justify or reflect the intergroup status hierarchy (Jost et al., 2004; Rubin \& Hewstone, 2004). One of these choices represented an indirect form of high status group favoritism that awarded equal points to both group members but that resulted in only the member from the high status group meeting the threshold for bonus points due to their two point advantage. In the first table of the appendix, this choice is represented by the $4 / 4$ option. This choice might also be described as "equal opportunities", although we prefer the term indirect high status group favoritism because it signifies the in-group favoring nature of this choice in our experimental context. The other choice represented a more direct form of high status group favoritism that did not rely on the high status group's advantage in order to be effective. This choice is represented by the $5 / 3$ option in the first table of the appendix.

Each of the eight points allocation tables included different people (i.e., different membership numbers), different starting points, and different totals needed for bonus points. In addition, the four allocation choices were presented in a randomized order for each table.

After they completed the points allocation tables, participants completed a series of other measures, including a measure of the perceived legitimacy of the intergroup situation. Participants were asked to think about the fact that the members from one of the groups always started the game with two more points than the members from the other group. They were then asked to indicate the extent to which they would use four legitimacy-related words (rational, justified, sensible, legitimate) and four illegitimacyrelated words (discrimination, differential treatment, prejudice, illegitimate) to describe this intergroup situation $(1=$ not at all; $7=$ very much $)$. The four legitimacy-related words have also been used by Iyer, Jetten, Branscombe, Jackson, and Youngberg (2013).

\section{Results and Discussion}

Perceived status legitimacy. The four legitimacy-related words had acceptable internal consistency $(\alpha=.69)$, as did the four illegitimacy-related words $(\alpha=.73)$. We subtracted mean scores on the illegitimacy words from mean scores on the legitimacy words to obtain a measure of the perceived legitimacy of the intergroup status hierarchy. Participants' mean score on this scale was significantly below zero $(M=-1.89, S D=$ $2.21), t(138)=-10.06, p<.001$, and this result held within each of the three conditions ( $p s<.001)$. Hence, consistent with our expectations, participants perceived the intergroup status hierarchy to be significantly more illegitimate than legitimate.

A one-way ANOVA showed no significant differences in perceived legitimacy between conditions, $F(2,136)=2.88, p=.060$. However, Least Significant Difference (LSD) post hoc tests found that participants in the low status group condition perceived 
the status hierarchy to be significantly less illegitimate $(M=-1.32, S D=2.36)$ than participants in the control condition $(M=-2.40, S D=.19), p=.019$. There were no other significant differences ( $p \mathrm{~s} \geq .139$; high status group $M=-1.99, S D=2.26$ ). Given the significant difference between the low status group and control conditions, we included perceived legitimacy as a covariate in our subsequent analyses. This variable did not act as a significant covariate and it did not affect our key results. Consequently, in order to facilitate comparison with Study 2, we excluded this covariate from the analyses that are reported below.

Points allocation choices. Each of the four allocation choices in each table had a $1 / 4(0.25)$ probability of being chosen by chance alone. Hence, the overall expected frequency of any one choice being selected across the 8 tables was 1.00. Following Bornstein et al. (1983, p. 335), we subtracted 1.00 from the frequency value for each of the four allocation choices so that a value of 0 indicated that the choice was chosen at chance levels, a value of -1 indicated that the choice was chosen below chance levels (i.e., actively avoided), and values ranging from 1 to 7 indicated that the choice was chosen above chance levels (i.e., actively selected). So, for example, a score of -1 would indicate that the choice was never chosen, a score of 0 would indicate that it was chosen at chance levels, and a score of 2 would indicate that it was chosen twice more than might be expected by chance.

Note that the four allocation choices were not independent from one another within each points allocation table: Selecting one choice necessarily precluded the selection of the other choices in that table. However, selecting an allocation choice in one table did not preclude the selection of different allocation choices in the other seven tables. Hence, the allocation choices could be considered independent from one another when computed across allocation tables.

One-way ANOVAs identified significant differences between conditions on all four choices, including competitive low status group favoritism, $F(2,136)=28.52$, $p<$ $.001, \eta_{\mathrm{p}}{ }^{2}=.30$, compensatory low status group favoritism, $F(2,136)=4.19, p=.017$, $\eta_{\mathrm{p}}{ }^{2}=.06$, indirect high status group favoritism, $F(2,136)=6.14, p=.003, \eta_{\mathrm{p}}{ }^{2}=.08$, and direct high status group favoritism, $F(2,136)=18.77, p<.001, \eta_{\mathrm{p}}{ }^{2}=.22{ }^{2}$ Table 1 provides the mean value for each choice within each condition.

Table 1 shows that participants in the low status group condition were significantly more likely than participants in the high status group condition or control condition to choose the competitive low status group favoritism option, and this choice was selected at greater than chance levels only in the low status group condition. However, our results also pointed to the influence of intergroup fairness. Table 1 shows that participants in all three conditions selected the compensatory favoritism option significantly more than chance. However, this option can only be interpreted as ingroup favoritism in the low status condition. Here, the awarding of more points to the in-group than to the out-group had the effect of compensating the in-group for its initial 
points disadvantage and leading to intergroup fairness. Hence, the compensatory favoritism choice enabled the low status in-group to do as well as the high status outgroup in terms of its points allocations but not necessarily better than the out-group.

Summary. Taken together, the present results indicate that, in a context in which the allocation system took prevailing status differences into account and allocation behavior could be used to affect the future status hierarchy, members of low status groups awarded their group more points using two strategies. A competitive favoritism strategy enabled their group to do better than the out-group in terms of its point allocations (i.e., social competition), and a compensatory favoritism strategy enabled their group to do as well as the out-group in terms of its allocations (i.e., intergroup fairness). This co-existence between the strategies of social competition and intergroup fairness has been noted in studies of equal status groups (e.g., Branthwaite et al., 1979). However, the present research provides the first demonstration that it plays a role in explaining why low status groups engage in in-group favoritism.

Notably, participants in the control condition chose the compensatory favoritism option significantly more than participants in the high status or low status group conditions. This makes sense because intergroup fairness is the most logical choice for people who are not affiliated with either of the groups that are involved in the study. However, it should be noted that their use of compensatory favoritism cannot be considered to be a form of in-group favoritism because they were not members of the low status group.

Participants who were members of the high status group selected the direct favoritism choices in favor of the high status group significantly more than chance levels and both the direct and indirect favoritism choices significantly more than participants who were members of the low status group condition or neither group. Again, these findings are not unexpected; they represent in-group favoritism on the part of the high status group members. Note, however, that the result for indirect high status group favoritism should be treated with some caution due to the relative low standard deviation in the low status group condition $(S D=.68)$.

\section{Study 2}

Study 1's effects occurred when participants perceived the intergroup status hierarchy to be relatively illegitimate. In Study 2, we investigated whether these effects persisted when the intergroup status hierarchy was perceived to be more legitimate. Social identity theory predicts that low status groups will engage in less in-group favoritism when the hierarchy is seen as both legitimate and stable (Tajfel \& Turner, 1979 , p. $37 \&$ p. 45$)$. Indeed, social identity theory predicts that low status groups may sometimes defer to the out-group's relatively high status and engage in out-group favoritism if they perceive the status system to be particularly legitimate and stable (Rubin \& Hewstone, 2004). However, a key aspect of our research paradigm is that the 
intergroup status hierarchy is not stable: Participants are informed that group status may change based on the number of points that each group accrues during the points

allocation task. Hence, in Study 2, although we provided a more legitimate basis for the initial intergroup status hierarchy, we expected participants to feel able to challenge this unstable hierarchy during the points allocation task. Consequently, we predicted that members of low status groups would continue to engage in both competitive and compensatory favoritism.

In Study 1, we explicitly informed participants that (a) the more points groups got the better, (b) one group started with more points than the other, and (c) the two groups would be compared in terms of their points. Consequently, we are fairly confident that participants considered the intergroup points difference as a suitable basis for establishing intergroup status. However, we did not explicitly test this assumption, and it is not necessarily the case that differences in initial intergroup points allocations can be equated with differences in intergroup status (Commons \& Lockwood, 1979a). Consequently, in Study 2, we included an explicit measure of group status in order to confirm that participants rated the high status group as being significantly higher in status than the low status group.

\section{Method}

Participants. Participants were 114 first-year psychology students (39 men, 75 women) at an Australian university who had a mean age of 19.38 years $(S D=4.27)$. There were 37 participants in the low status group, 38 in the high status group, and 39 in a control condition, who belonged to neither group.

Procedure. The procedure was similar to Study 1, with the following exceptions. A bogus cover story was used to create the perception of a relatively legitimate status hierarchy. Specifically, participants were told that the study consisted of two parts, and that Part 1 had taken place four weeks prior to the current part (Part 2). Participants read that, in Part 1, a 10-person Red group and a 10-person Green group had taken part in a group creativity competition that involved thinking of new ways to advertise the university to prospective students. Participants in the low status group read that a panel of impartial experts had judged the quality of each group's ideas and agreed that the Green Group's ideas were more novel, creative, and effective than the Red Group's ideas. Consequently, the Green Group (i.e., the out-group) was declared the winner of Part 1 of the study and, as a reward, Green Group members were given an advantage in Part 2. This cover story provided an explanation for the Green group's two-point advantage during the points allocation task. In order to experimentally manipulate group status, the "Red Group" and "Green Group" labels were interchanged in the high status group and control conditions.

Participants read that, in Part 2 of the study, there were 20 people in each group, including the 10 people who had belonged to each group during Part 1 and 10 new 
members who had joined each group for Part 2. There were also 20 people who had not been assigned to either group (control condition).

Participants completed a series of measures, including the measure of perceived legitimacy of the intergroup status hierarchy that was used in Study 1. In addition, in order to confirm the effectiveness of our manipulation of group status, we asked participants to rate members of each group on five positive dimensions that would be expected to be relevant to group performance during the creativity competition: $\mathrm{co}$ ordinated, creative, productive, effective, and innovative $(1=$ not at all, $7=$ very much $)$. Participants then completed the points allocation task using the same tables as in the appendix.

\section{Results and Discussion}

Group status check. The five status-relevant items had good internal consistency when participants rated the high status group $(\alpha=.93)$ and the low status group $(\alpha=.95)$. Consequently, we computed the mean scores for each of these measures. A 2 (condition: high status group/control group/low status group) x 2 (target group: high status/low status) revealed a significant main effect of target group, $F(1$, $110)=124.82, p<.001, \eta_{\mathrm{p}}{ }^{2}=.53$ : Consistent with expectations, people rated members of the high status group as possessing significantly more status-relevant traits $(M=5.41$, $S D=.09)$ than members of the low status group $(M=4.09, S D=.10)$. There was also a significant main effect of condition, $F(2,110)=3.88, p=.024, \eta_{\mathrm{p}}{ }^{2}=.07$. LSD post hoc tests showed that participants in the control group rated both groups as possessing significantly more status-relevant traits $(M=5.04, S D=.13)$ than participants in either the high status group condition $(M=4.57, S D=.13, p=.011)$ or the low status group condition $(M=4.65, S D=.13, p=.033)$. Importantly, however, this effect of condition did not qualify the effect of target group, $F(2,110)=1.09, p=.340, \eta_{\mathrm{p}}{ }^{2}=.02$. Hence, the effectiveness of our manipulation of group status was comparable within each of our three conditions. Confirming this conclusion, paired sample $t$ tests conducted within each condition showed that participants always perceived the high status group to possess more status-relevant traits than the low status group $(p s<.001)$.

Perceived status legitimacy. The four legitimacy words had good internal consistency $(\alpha=.90)$, as did the four illegitimacy words $(\alpha=.80)$. As in Study 1 , we subtracted mean scores on the illegitimacy words from mean scores on the legitimacy words to obtain a measure of the perceived legitimacy of the intergroup status hierarchy. Participants' mean score on this scale was significantly above zero $(M=1.56, S D=$ $2.04), t(113)=8.18, p<.001$, and this result held within each of the three conditions ( $p$ s $<.001)$. Hence, consistent with our expectations, participants perceived the intergroup status hierarchy to be significantly more legitimate than illegitimate. A one-way ANOVA showed no significant differences in perceived legitimacy between conditions, $F(2,111)=.62, p=.539$, and additional LSD post hoc tests found no significant 
differences between conditions ( $p \mathrm{~s} \geq .282$; low status group condition $M=1.49, S D=$ 2.20; control condition $M=1.85, S D=2.27$; high status group condition $M=1.34, S D$ $=1.59$ ).

Points allocation choices. As in Study 1, we subtracted 1.00 from the frequency value for each of the four allocation choices so that a value of 0 indicated that the choice was chosen at chance levels. One-way ANOVAs identified significant differences between conditions on competitive low status group favoritism, $F(2,111)=$ $37.10, p<.001, \eta_{\mathrm{p}}{ }^{2}=.40$, and direct high status group favoritism, $F(2,111)=3.74, p=$ $.027, \eta_{\mathrm{p}}{ }^{2}=.06$. Table 2 provides the mean value for each choice within each condition.

Table 2 shows that, consistent with predictions, members of the low status group were significantly more likely than participants in the other two conditions to choose the competitive low status group favoritism option, and this choice was selected at greater than chance levels only in the low status group condition.

As in Study 1, participants in all three conditions selected the compensatory low status group favoritism option significantly more than chance. Again however, this option can only be interpreted as in-group favoritism in the low status condition: Here, awarding more points to the in-group than to the out-group compensated the in-group for its initial points disadvantage and led to intergroup fairness.

Finally, as in Study 1, members of the high status group chose direct and indirect favoritism in favor of the high status group significantly more than members of the low status group condition.

Interestingly, there was no evidence that members of low status groups showed out-group favoritism in Study 2, even though they acknowledged the legitimacy of the intergroup status hierarchy (cf. Jost et al., 2004; Rubin \& Hewstone, 2004). This absence of out-group favoritism may be because our points allocation tables provided participants with a relatively direct method of changing the status quo and, consequently, although the status system was more legitimate, it was also unstable.

\section{General Discussion}

The present research investigated whether the members of low status groups show in-group favoritism as a competitive strategy, a compensatory strategy, or both. We distinguished these strategies by providing a context in which an intergroup reward allocation system was both tied to a prevailing status hierarchy and had the potential to either maintain or change it.

In two studies, we found that participants in low status groups showed both competitive and compensatory favoritism at greater than chance levels, and that they showed competitive favoritism significantly more than participants in a high status group or control condition. These results suggest that members of low status groups use in-group favoritism in order to achieve both intergroup fairness and high in-group status. 
Importantly, our results generalized from a relatively illegitimate status hierarchy (Study 1) to a relatively legitimate status hierarchy (Study 2). This finding suggests that members of low status groups are motivated to try to change unstable status systems through competitive and compensatory favoritism, regardless of whether those systems are perceived to be illegitimate or legitimate. It is notable, however, that the difference in perceived legitimacy between Studies 1 and 2 was not as large as it could have been (Study 1: $M=-1.89, S D=2.21$; Study 2: $M=1.56, S D=2.04$ ). In order to provide a more powerful test of the effect of status legitimacy, future research should experimentally manipulate legitimacy using methods that create a clearer divergence in perceived legitimacy.

It is also worth noting that the compensatory favoritism option tended to dominate in all conditions of both studies. This finding is consistent with previous work that has noted the prominent role of intergroup fairness in intergroup allocation tasks (e.g., Branthwaite et al., 1979; Bornstein et al., 1983; Platow \& McClintock, 1990).

\section{Implications, Limitations, and Directions for Future Research}

The present research shows that members of low status groups may sometimes engage in in-group favoritism in order to achieve intergroup fairness. This is a particularly innovative finding. Most previous minimal group studies have investigated intergroup resource distribution between groups that have equal status. Under these conditions, intergroup fairness reflects or justifies an intergroup equality and leads to no social change. In contrast, the present research shows that, in the context of unequal intergroup status relations, intergroup fairness expressed via compensatory favoritism can function as a method for social change.

The present research findings also help to redress the balance of research attention from low status groups' out-group favoritism to their in-group favoritism. Low status groups' out-group favoritism has been interpreted as either an active attempt to justify the status system (Jost et al., 2004) or a passive reflection of this system (Rubin \& Hewstone, 2004). The present research demonstrates that low status groups' in-group favoritism may also serve different functions: compensating for current inequality and/or competing for future status.

One limitation of the present research is that we did not provide direct evidence of the motivational processes that underlie low status groups' compensatory favoritism. Future research in this area should focus on this issue. It is possible that compensatory favoritism is related to normative concerns (Branthwaite et al., 1979; Singh et al., 1998), hierarchy-attenuating ideologies (Pratto et al.,1994), and/or interpersonal social value orientation (Platow et al., 1990). In addition, compensatory favoritism may be connected with distributive justice based on a group's need rather than its merit. Certainly, there is evidence that members of low status groups are more attuned to the 
principle of need-based distributive justice (for a review, see Crosby, Iyer, \& Sincharoen, 2006).

It is also possible that compensatory favoritism is motivated by social identity concerns. Although intergroup fairness does not meet the need for a positive social identity for low status groups, it may nonetheless help to avoid a negative social identity. Future research in this area should investigate this negative identity avoidance hypothesis.

The present research also demonstrated that members of low status groups appear to seek a balance between competitive and compensatory favoritism. However, it is likely that this balance may tip towards one or other extreme for different social groups and in different social situations. For example, gay men and women may favor their low status group because they seek equality with straight men and women in having the right to marry their partners. In this case, in-group favoritism is enacted more with the aim of achieving intergroup equality rather than relatively high in-group status. In contrast, members of relatively low status countries might engage in in-group favoritism not because they seek equality with other countries but because they are striving for a relatively high in-group status.

Finally, future research should confirm that the present research findings generalize from the specific methodology that we used. In particular, it is important to demonstrate that our results generalize from the particular points allocation tables that we used to other methods that assess compensatory and competitive favoritism. In addition, future research in this area should employ a more consequential paradigm that uses real world rewards (e.g., money) rather than points.

In summary, the present research found that members of low status groups engage in in-group favoritism partly to be as good as the high status out-group and partly to be better than the out-group. These findings support the general idea that ingroup favoritism can serve different functions depending on the intergroup context (Scheepers et al., 2006). 


\section{Acknowledgements}

This work was supported by a Discovery Project grant from the Australian Research Council awarded to the third author [grant number DP120100053]. 


\section{Conflict of Interest Statement}

The Authors declare that there is no conflict of interest. 


\section{References}

Bettencourt, B. A., Charlton, K., Dorr, N., \& Hume, D. L. (2001). Status differences and in-group bias: A meta-analytic examination of the effects of status stability, status legitimacy, and group permeability. Psychological Bulletin, 127, 520-542. doi: 10.1037/0033-2909.127.4.520

Bornstein, G., Crum, L., Wittenbraker, J., Harring, K., Insko, C. A., \& Thibaut, J. (1983). On the measurement of social orientations in the minimal group paradigm. European Journal of Social Psychology, 13, 321-350. doi: 10.1002/ejsp.2420130402

Branthwaite, A., Doyle, S., \& Lightbown, N. (1979). The balance between fairness and discrimination. European Journal of Social Psychology, 9, 149-163. doi: 10.1002/ejsp.2420090204

Brewer, M. B. (1979). Ingroup bias in the minimal intergroup situation: A cognitive motivational analysis. Psychological Bulletin, 86, 307-324. doi: 10.1037/00332909.86.2.307

Commins, B., \& Lockwood, J. (1979a). The effects of status differences, favoured treatment and equity on intergroup comparisons. European Journal of Social Psychology, 9, 281-289. doi: 10.1002/ejsp.2420090306

Commins, B., \& Lockwood, J. (1979b). Social comparison and social inequality: An experimental investigation of intergroup behaviour. British Journal of Social and Clinical Psychology, 18, 285-289. doi: 10.1111/j.2044-8260.1979.tb00338.x

Crosby, F. J., Iyer, A., \& Sincharoen, S. (2006). Understanding affirmative action. Annual Review of Psychology, 57, 585-611. doi: 10.1146/annurev.psych.57.102904.190029

Iyer, A., Jetten, J., Branscombe, N. R., Jackson, S., \& Youngberg, C. (2013). The difficulty of recognizing less obvious forms of group-based discrimination. Manuscript in preparation. The University of Queensland, Australia.

Jost, J. T., Banaji, M. R., \& Nosek, B. A. (2004). A decade of system justification theory: Accumulated evidence of conscious and unconscious bolstering of the status quo. Political Psychology, 25, 881-919. doi: 10.1111/j.14679221.2004.00402.x

Klein, O., \& Azzi, A. (2001). Do high status groups discriminate more? Differentiating between social identity and equity concerns. Social Behavior and Personality, 29, 209-221. doi: 10.2224/sbp.2001.29.3.209

Mullen, B., Brown, R., \& Smith, C. (1992). Ingroup bias as a function of salience, relevance and status: An integration. European Journal of Social Psychology, 22, 103-122. doi: 10.1002/ejsp.2420220202

Mummendey, A., Simon, B., Dietze, C., Grunert, M., Haeger, G., Kessler, S.,...Schaferhoff, S. (1992). Categorization is not enough: Intergroup discrimination in negative outcome allocation. Journal of Experimental Social 
Psychology, 28, 125-144. doi: 10.1016/0022-1031(92)90035-I

National Organization for Women. (2013). Retrieved from http://www.now.org/issues/economic/factsheet.html

Platow, M. J., McClintock, C. G., \& Liebrand, W. B. G. (1990). Predicting intergroup fairness and ingroup bias in the minimal group paradigm. European Journal of Social Psychology, 20, 221-239. doi: 10.1002/ejsp.2420200304

Pratto, F., Sidanius, J., Stallworth, L. M., \& Malle, B. F. (1994). Social dominance orientation: A personality variable predicting social and political attitudes. Journal of Personality and Social Psychology, 67, 741-763. doi:10.1037/00223514.67.4.741

Reichl, A. J. (1997). Ingroup favouritism and outgroup favouritism in low status minimal groups: Differential responses to status-related and status-unrelated measures. European Journal of Social Psychology, 27, 617-633. doi: 10.1002/(SICI)1099-0992

Rubin, M., \& Hewstone, M. (2004). Social identity, system justification, and social dominance: Commentary on Reicher, Jost et al., and Sidanius et al. Political Psychology, 25, 823-844. doi: 10.1111/j.1467-9221.2004.00400.x

Sachdev, I., \& Bourhis, R. Y. (1984). Minimal majorities and minorities. European Journal of Social Psychology, 14, 35-52. doi: 10.1002/ejsp.2420140104

Sachdev, I., \& Bourhis, R. Y. (1987). Status differentials and intergroup behaviour. European Journal of Social Psychology, 17, 277-293. doi: 10.1002/ejsp.2420170304

Sachdev, I., \& Bourhis, R. Y. (1991). Power and status differentials in minority and majority group relations. European Journal of Social Psychology, 21, 1-24. doi: 10.1002/ejsp.2420210102

Scheepers, D., Spears, R., Doosje, B., \& Manstead, A. S. R. (2006). Diversity in ingroup bias: Structural factors, situational features, and social functions. Journal of Personality and Social Psychology, 90, 944-960. doi: 10.1037/00223514.90.6.944

Singh, R., Choo, W. M., \& Poh, L. L. (1998). In-group bias and fair-mindedness as strategies of self-presentation in intergroup perception. Personality and Social Psychology Bulletin, 24, 147-162. doi: 10.1177/0146167298242004

Tajfel, H., \& Turner, J. C. (1979). An integrative theory of intergroup conflict. In S. Worchel \& W. G. Austin (Eds.), The social psychology of intergroup relations (pp. 33-47). Monterey, CA: Brooks-Cole.

Turner, J. C. (1975). Social comparison and social identity: Some prospects for intergroup behaviour. European Journal of Social Psychology, 5, 5-34. doi: 10.1002/ejsp.2420050102

Turner, J. C., \& Brown, R. J. (1978). Social status, cognitive alternatives and intergroup relations. In H. Tajfel (Ed.), Differentiation between social groups: Studies in 
the social psychology of intergroup relations (pp. 201-234). London: Academic Press.

van Knippenberg, A. (1984). Intergroup differences in group perception. In H Tajfel (Ed.), The social dimension: Developments in European social psychology (Vol. 2, pp. 560-578). Cambridge, UK: Cambridge University Press. 


\section{Footnotes}

1. Compensatory favoritism can be considered as a form of affirmative action or equal outcomes because it provides more resources to one group than to another based on a pre-existing inequality between the two groups with the aim of achieving intergroup equality. The key difference is that compensatory favoritism involves members of low status groups favoring their group, whereas affirmative action or equal outcomes can be enacted by anyone, including out-group members.

2. Gender did not show any main effects or interactions with condition in either Study 1 or Study 2 ( $p s \geq .163$ ). 
Table 1

Mean Values for Each Resource Allocation Choice in Study 1

\begin{tabular}{lcccc}
\hline & \multicolumn{4}{c}{ Resource allocation choice } \\
\cline { 2 - 5 } Condition & $\begin{array}{c}\text { Competitive } \\
\text { low status group } \\
\text { favoritism }\end{array}$ & $\begin{array}{c}\text { Compensatory } \\
\text { low status } \\
\text { group } \\
\text { favoritism }\end{array}$ & $\begin{array}{c}\text { Indirect high } \\
\text { status group } \\
\text { favouritism }\end{array}$ & $\begin{array}{c}\text { Direct high } \\
\text { status group } \\
\text { favoritism }\end{array}$ \\
\hline Low status & $2.38_{\mathrm{b}}^{*}$ & $2.96_{\mathrm{a}}^{*}$ & $-.60_{\mathrm{b}} *$ & $-.73_{\mathrm{b}} *$ \\
group & $(3.02)$ & $(3.16)$ & $(.68)$ & $(.64)$ \\
Control & $.02 \mathrm{a}$ & $4.48_{\mathrm{b}} *$ & $-.14_{\mathrm{b}}$ & $-.39_{\mathrm{b}}$ \\
condition & $(1.75)$ & $(2.87)$ & $(1.73)$ & $(1.39)$ \\
High status & $-.72_{\mathrm{a}}^{*}$ & $2.72_{\mathrm{a}}^{*}$ & $.53_{\mathrm{a}}$ & $1.47_{\mathrm{a}}^{*}$ \\
group & $(.83)$ & $(3.32)$ & $(2.04)$ & $(2.85)$ \\
\hline
\end{tabular}

Note. Standard deviations are shown in parentheses. Means with different subscripts differ significantly between conditions according to LSD post hoc tests ( $p$ s <.05). Means with asterisks differ significantly from zero $(p s \leq .001)$. 
Table 2

Mean Values for Each Resource Allocation Choice in Study 2

\begin{tabular}{lcccc}
\hline & \multicolumn{4}{c}{ Resource allocation choice } \\
\cline { 2 - 5 } Condition & $\begin{array}{c}\text { Competitive low } \\
\text { status group } \\
\text { favoritism }\end{array}$ & $\begin{array}{c}\text { Compensatory } \\
\text { low status } \\
\text { group } \\
\text { favoritism }\end{array}$ & $\begin{array}{c}\text { Indirect high } \\
\text { status group } \\
\text { favoritism }\end{array}$ & $\begin{array}{c}\text { Direct high } \\
\text { status group } \\
\text { favoritism }\end{array}$ \\
\hline Low status & $2.68_{\mathrm{b}}^{*}$ & $1.73_{\mathrm{b}} *$ & $-.19_{\mathrm{b}}$ & $-.41_{\mathrm{b}} *$ \\
group & $(2.87)$ & $(2.47)$ & $(1.61)$ & $(1.21)$ \\
Control & $-.05_{\mathrm{a}}$ & $3.18_{\mathrm{a}}^{*}$ & $.67_{\mathrm{ab}}$ & $.18_{\mathrm{ab}}$ \\
condition & $(1.26)$ & $(2.84)$ & $(2.11)$ & $(1.54)$ \\
High status & $-.76_{\mathrm{a}}^{*}$ & $2.97_{\mathrm{ab}} *$ & $.79_{\mathrm{a}}^{*}$ & $.68_{\mathrm{a}}$ \\
group & $(.59)$ & $(3.12)$ & $(2.18)$ & $(2.26)$ \\
\hline
\end{tabular}

Note. Standard deviations are shown in parentheses. Means with entirely different subscripts differ significantly between conditions according to LSD post hoc tests ( $p s<$ $.05)$. Means with asterisks differ significantly from zero $(p s \leq .05)$. 


\section{Appendix: Status-Embedded Points Allocation Tables Used in the Low Status Group Condition of Studies 1 and 2}

\begin{tabular}{|l|c|c|c|c|c|}
\hline \multirow{2}{*}{ Total Needed for Bonus Points: 11 points } \\
Person Identification & $\begin{array}{c}\text { Each Person's } \\
\text { Starting Points }\end{array}$ & \multicolumn{5}{c|}{ My Allocation to Each Person } \\
\hline Member 45 of the Green Group & $\mathbf{8}$ & 5 & 3 & 4 & 2 \\
\hline Member 50 of the Red Group & $\mathbf{6}$ & 3 & 5 & 4 & 6 \\
\hline
\end{tabular}

Total Needed for Bonus Points: 7 points

Each Person's

Person Identification Starting Points

My Allocation to Each Person

Member 16 of the Green Group Member 34 of the Red Group

+

6

\begin{tabular}{|c|c|c|c|c|c|}
\hline \multicolumn{6}{|c|}{ Total Needed for Bonus Points: 12 points } \\
\hline Person Identification & $\begin{array}{l}\text { Each Person's } \\
\text { Starting Points }\end{array}$ & \multicolumn{4}{|c|}{ My Allocation to Each Person } \\
\hline Member $\mathbf{3 1}$ of the Green Group & 9 & 5 & 4 & 2 & 3 \\
\hline Member $\mathbf{1 8}$ of the $\mathbf{R e d}$ Group & 7 & 3 & 4 & 6 & 5 \\
\hline
\end{tabular}

\section{Total Needed for Bonus Points: 6 points}

Person Identification

\begin{tabular}{|l|}
\hline Member $\mathbf{3 5}$ of the Green Group \\
\hline Member $\mathbf{1 2}$ of the Red Group
\end{tabular}
Each Person's Starting Points My Allocation to Each Person

\begin{tabular}{|c|c|c|c|c|c|}
\hline \multicolumn{2}{|c|}{ Total Needed for Bonus Points: $\mathbf{4}$ points } & & & & \\
\hline Person Identification & $\begin{array}{l}\text { Each Person's } \\
\text { Starting Points }\end{array}$ & \multicolumn{4}{|c|}{ My Allocation to Each Person } \\
\hline Member $\mathbf{2 3}$ of the Green Group & 2 & 1 & 2 & 3 & 4 \\
\hline Member $\mathbf{1 9}$ of the Red Group & $\mathbf{0}$ & 5 & 4 & 3 & 2 \\
\hline
\end{tabular}

\section{Total Needed for Bonus Points: 8 points}

\section{Person Identification}

Each Person's Starting Points

My Allocation to Each Person

\begin{tabular}{|l|l|l|l|l|l|}
\hline Member $\mathbf{1 0}$ of the Green Group & $\mathbf{4}$ & 6 & 4 & 3 & 5 \\
\hline Member $\mathbf{3 0}$ of the Red Group & $\mathbf{2}$ & 4 & 6 & 7 & 5 \\
\hline
\end{tabular}




\begin{tabular}{|l|c|c|c|c|c|}
\hline \multirow{2}{*}{ Total Needed for Bonus Points: 9 points } \\
Person Identification & $\begin{array}{c}\text { Each Person's } \\
\text { Starting Points }\end{array}$ & \multicolumn{5}{c|}{ My Allocation to Each Person } \\
\hline Member 6 of the Green Group & $\mathbf{7}$ & 3 & 2 & 4 & 1 \\
\hline Member 41 of the Red Group & $\mathbf{5}$ & 3 & 4 & 2 & 5 \\
\hline
\end{tabular}

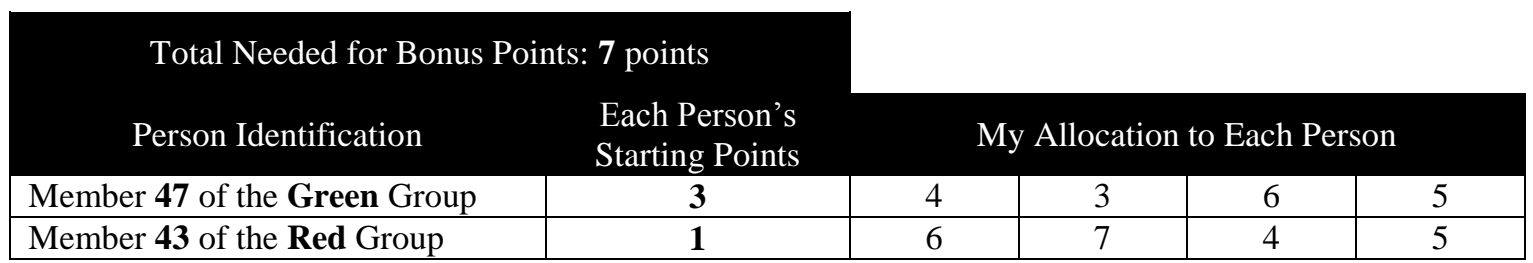

